\title{
Retinal microvascular parameters are not associated with diabetes in the Northern Ireland Cohort for the Longitudinal Study of Ageing
}

\author{
Rachael Ann O'Neill ${ }^{1}$ Alexander Peter Maxwell ${ }^{1}$ Frank Kee ${ }^{1} \cdot$ lan Young ${ }^{1} \cdot$ Bernadette McGuinness ${ }^{1} \cdot$ Ruth E. Hogg $^{1}$. \\ Sharon Cruise ${ }^{1} \cdot$ Gareth J. McKay ${ }^{1}$ (i)
}

Received: 17 September 2020 / Accepted: 26 June 2021 / Published online: 9 July 2021

(c) The Author(s) 2021

\begin{abstract}
Background The retinal microvasculature offers unique non-invasive evaluation of systemic microvascular abnormalities. Previous studies reported associations between retinal microvascular parameters (RMPs) and diabetes. The aim of this study was to assess associations between RMPs and diabetes in a cross-sectional analysis of older persons from the Northern Ireland Cohort for the Longitudinal Study of Ageing (NICOLA).

Methods RMPs (central retinal arteriolar/venular equivalents, arteriolar to venular ratio, fractal dimension, and tortuosity) were measured from optic disc-centred fundus images using semi-automated software. Associations were assessed between RMPs and diabetes status with adjustment for potential confounders.

Results Data were included for 1762 participants with 209 classified as having diabetes. Participants had a mean age of $62.1 \pm 8.5$ years, and $54 \%$ were female. As expected, participants with diabetes had significantly higher mean glycated haemoglobin A1c compared to participants without diabetes $(57.4 \pm 17.6 \mathrm{mmol} / \mathrm{mol}$ versus $37.0 \pm 4.2 \mathrm{mmol} / \mathrm{mol}$, respectively). In unadjusted and minimally adjusted regression, arteriolar to venular ratio, arteriolar tortuosity and venular tortuosity were significantly associated with diabetes (minimally adjusted odds ratio [OR] $=0.85 ; 95 \%$ confidence intervals [CIs] $0.73,0.99$; $P=0.04, \mathrm{OR}=1.18 ; 95 \% \mathrm{CI} 1.02,1.37 ; P=0.03$ and $\mathrm{OR}=1.20 ; 95 \% \mathrm{CI} 1.04,1.38 ; P=0.01$, respectively), although all failed to remain significant following adjustment for potential confounders. No additional associations between other RMPs and diabetes were detected.

Conclusion Despite previously reported associations between diabetes and RMPs, our study failed to corroborate these associations in an older community-based cohort.
\end{abstract}

Keywords Diabetes $\cdot \mathrm{HbA1c} \cdot$ Retinal microvascular parameters

\section{Background}

Global life expectancy is increasing and in Northern Ireland, the most rapidly growing demographic group are those $>50$ years, highlighting the importance of research on age-related conditions [1]. Diabetes is imposing an increasing burden on public health systems, and older individuals are more likely to be over-represented among those with diabetes [2, 3]. Measurement of glycated haemoglobin A1c (HbA1c) is a diagnostic test that reflects the average blood sugar level over the previous $2-3$ months, enabling effective

Gareth J. McKay

g.j.mckay@qub.ac.uk

1 Centre for Public Health, Queens University Belfast, Belfast, Ireland monitoring of intervention strategies to lower blood sugar levels and associated risk of diabetic complications [4, 5]. The pathogenesis of diabetes is complex leading to microvascular dysfunction [6,7], following prolonged periods of chronic hyperglycaemia that commonly leads to damage to the kidneys, retinas and peripheral nervous system and increased cardiovascular risk [8]. The retinal microvasculature comprises a collection of small arterioles and venules. Their examination provides a unique and non-invasive opportunity to evaluate systemic microvasculature variation and abnormalities that may reflect similar changes elsewhere within the microvascular system $[3,9,10]$.

Advances in retinal imaging software and analysis applications can provide for opportunistic identification of microangiopathic variation in the eye that may reflect similar microvascular anomalies elsewhere in the body $[11,12]$. 
Additionally, variation in retinal microvascular parameters (RMPs) may reflect aetiological mechanisms that are characteristic of diabetes pathogenesis such as oxidative stress, endothelial dysfunction, inflammation and hypertension [13-17]. A recent systematic review and meta-analysis of several population-based studies reported that increased retinal venular dilation, but not retinal arteriolar narrowing, was significantly associated with an increased risk for diabetes [3]. Nevertheless, although most prospective studies reported associations between retinal venular dilation and diabetes, these data have not always been consistent with cross-sectional analyses [3, 18-23]. Other RMPs are reported to be associated with diabetes. Increased retinal arteriolar [24] and venular tortuosity [24, 25] were reported to be significantly increased in individuals with type 2 diabetes or elevated HbA1c. Yau et al. reported increased fractal dimensions associated with impaired glucose tolerance and/ or type 2 diabetes [26]. In contrast, Broe et al. found that decreased fractal dimensions were associated with greater risk of complications in type 1 diabetes [27]. As such, the aim of this study was to assess RMPs in association with measures of $\mathrm{HbAlc}$ and diabetes status in a cross-sectional analysis of older persons from the Northern Ireland Cohort for the Longitudinal Study of Ageing (NICOLA).

\section{Methods}

\section{Study population}

NICOLA is a longitudinal cohort study of 8468 community dwelling men and women aged 50 years and over, resident in Northern Ireland (individuals in care homes or other residential institutions were excluded at baseline) [28]. The study, established in 2013, has three main components: a computeraided personal interview (CAPI), a self-completion questionnaire and health assessment. The CAPI was extensive in scope and included assessment of demographic, social and health-related factors. Measures of cardiovascular, physical, cognitive and visual function were determined; biological samples were collected and a visual health assessment undertaken that included retinal fundus photography. Written informed consent was obtained from participants prior to taking part, following ethical approval from the School of Medicine, Dentistry and Biomedical Sciences Ethics Committee, Queen's University Belfast (SREC 12/23) and in accordance with the Helsinki Declaration.

\section{Measurement of retinal images}

Retinal photography was performed following dilation from a single drop of $1 \%$ tropicamide using a Canon CX-1 Digital Fundus Camera (Canon USA, Melville, NY, USA). RMPs (central retinal arteriolar equivalent [CRAE], central retinal venular equivalents [CRVE], arteriolar to venular ratio [AVR], fractal dimension and tortuosity) were measured from optic disc-centred fundus images and analysis undertaken using the semi-automated software Vessel Assessment and Measurement Platform for Images of the Retina (VAMPIRE; VAMPIRE group, Universities of Dundee and Edinburgh, Scotland, Version 3.1; Fig. 1), by a trained grader, blinded to participant data [29, 30]. Analysis was undertaken on images taken from the left eye except when unavailable or of insufficient quality, in which case the right eye image was used. A paired samples t-test compared a sub-sample of left and right eye measurements. Intraclass correlation coefficients (ICCs) were calculated to assess intergrader reliability with mean values of 0.87 (CRAE) and 0.91 (CRVE).

\section{Measurement and classification of diabetic status}

Diabetes status was categorised on the basis of selfreported diabetes at CAPI, use of diabetic medications or $\mathrm{HbA} 1 \mathrm{c} \geq 48 \mathrm{mmol} / \mathrm{mol}$. Participants were excluded if diabetes status or retinal images were missing or of insufficient quality for analysis (Fig. 2).

\section{Other variables}

Mean arterial blood pressure (MABP) was calculated as the average of two individual systolic blood pressure (SBP) and diastolic blood pressure (DBP) measurements $(2 / 3$

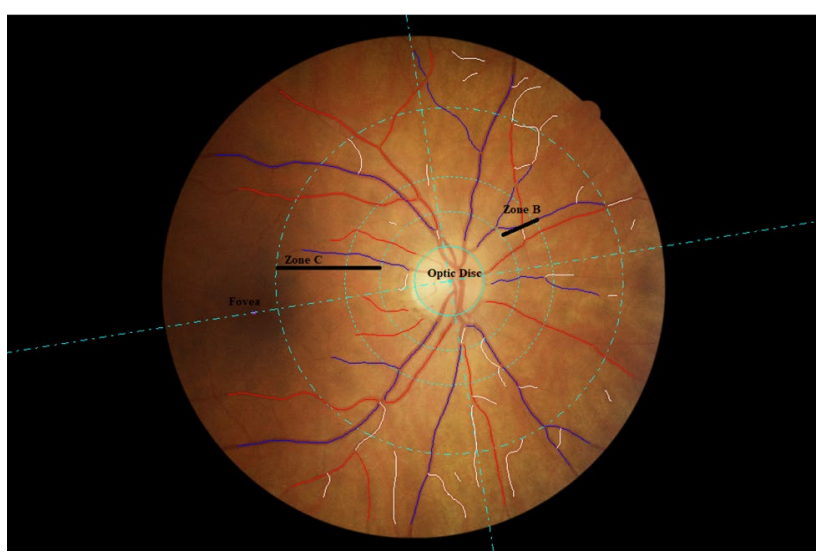

Fig. 1 Retinal fundus image assessed using the VAMPIRE software. Optic disc-centred retinal fundus image assessed using the Vessel Assessment and Measurement Platform for Images of the Retina (VAMPIRE) software. Arterioles (red), venules (blue) and deleted segments (white) are indicated. The retinal microvascular parameters for arteriolar and venular calibre (CRAE, CRVE and AVR) are calculated from measurements captured in zones B (1.0 to 1.5 optic disc diameters from the centre of the optic disc). Fractal dimension and tortuosity are calculated from measurements captured in zone C (1.0 to 2.5 optic disc diameters from the centre of the optic disc) 


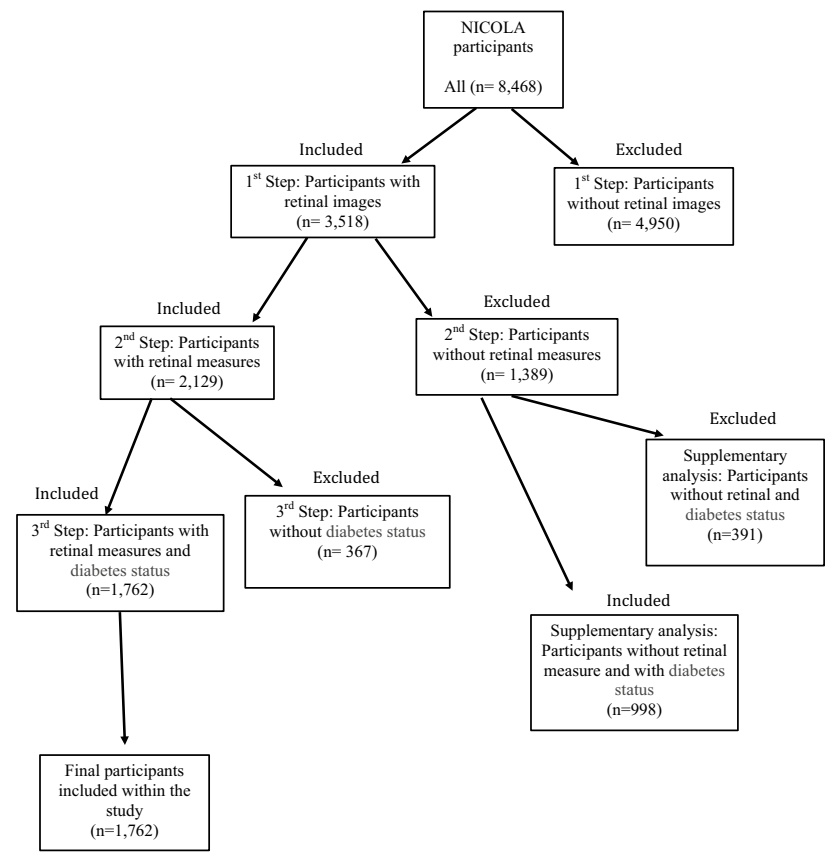

Fig. 2 A flow chart of participant inclusion and exclusion criteria

DBP $+1 / 3$ SBP). Smoking status was categorised as current smokers versus non-smokers. Alcohol consumption was categorised: non-drinker, light drinker (1-7 units per week), moderate to heavy drinker ( $>7$ units per week). Cardiovascular disease (CVD) was characterised by selfreport on a history of angina, heart attack, congestive heart failure or stroke. Participant height was measured to the nearest centimetre using a seca 240 wall-mounted measuring rod, and weight was measured in kilograms using seca electronic floor scales. Triglycerides and high- and lowdensity lipoprotein (HDL and LDL) were measured from individual participant blood samples. Physical activity (PA) was categorised as inactive, low, moderate or highly active in accordance with the Global Physical Activity Questionnaire (GPAQ), scored by calculating the average time per day spent in each activity domain (work, transport and leisure) and the intensity of PA during that time [31, 32].

\section{Statistical analysis}

All analyses were performed using Statistical Package for Social Sciences (Version 24.0. Armonk, NY: IBM Corp). Before inclusion in regression models, all RMPs were transformed into standardised Z-scores (a standard deviation [SD] increase from the mean). Population characteristics were summarised as mean and SD for continuous variables or frequencies and percentages for categorical variables. Between-group differences were assessed using chi-squared tests to compare categorical variables for demographic and clinical factors and t-tests for continuous variables according to diabetes status. Binary logistic regression was used to evaluate associations between RMPs and diabetic status. Additional sensitivity analyses included excluding control participants with pre-diabetes (HbA1c values between 42 and $47 \mathrm{mmol} / \mathrm{mol}$ ) and linear regression modelling to evaluate associations between RMPs and HbAlc. Minimally adjusted regression models included age and sex, while fully adjusted models also included smoking status, CVD, alcohol consumption, MABP, physical activity level, BMI, triglycerides and HDL and LDL. $\mathrm{P}<0.05$ was considered statistically significant.

\section{Results}

Data for retinal imaging of sufficient quality and $\mathrm{HbA1c}$ was available for 1762 participants who attended the health assessment; 209 were classified as diabetic (12\%). Table 1 provides study participant summary characteristics. Participants had a mean age of $62.1 \pm 8.5$ years, and $54 \%$ were female. Mean $\mathrm{HbAlc}$ was $39.4 \pm 9.8 \mathrm{mmol} / \mathrm{mol}$, MABP was $98.0 \pm 12.3 \mathrm{~mm} \mathrm{Hg}$, and $27 \%$ were characterised by high levels of physical activity. As expected, participants with diabetes had significantly higher mean $\mathrm{HbA} 1 \mathrm{c}(57.4 \mathrm{mmol} / \mathrm{mol}$ versus $37.0 \mathrm{mmol} / \mathrm{mol}$, respectively), lower estimated glomerular filtration rate $\left(77.4 \mathrm{ml} / \mathrm{min} / 1.73 \mathrm{~m}^{2}\right.$ versus $82.8 \mathrm{ml} /$ $\left.\mathrm{min} / 1.73 \mathrm{~m}^{2}\right)$, were hypertensive $(43.1 \%$ versus $35.6 \%$; defined as a mean systolic blood pressure $\geq 140 \mathrm{~mm} \mathrm{Hg}$ or mean diastolic blood pressure $\geq 90 \mathrm{~mm} \mathrm{Hg}$ ) and tended to be older $(65.1 \pm 9.0$ years versus $61.7 \pm 8.4$ years $)$ than those without diabetes (Table 1). They also had higher mean triglycerides $(1.9 \pm 1.2 \mathrm{mmol} / \mathrm{L}$ versus $1.6 \pm 0.9 \mathrm{mmol} / \mathrm{L}$, respectively) but lower mean HDL and LDL cholesterol (HDL $1.4 \pm 0.4 \mathrm{mmol} / \mathrm{L}$ versus $1.7 \pm 0.5 \mathrm{mmol} / \mathrm{L}$ and $\mathrm{LDL}$ $2.8 \pm 1.1 \mathrm{mmol} / \mathrm{L}$ versus $3.5 \pm 1.1 \mathrm{mmol} / \mathrm{L}$ ). A higher percentage of participants with diabetes were more likely to refrain from alcohol consumption (34\% versus $21 \%$ ), have a higher BMI $\left(31.4 \pm 5.7 \mathrm{~kg} / \mathrm{m}^{2}\right.$ versus $28.2 \pm 4.7 \mathrm{~kg} / \mathrm{m}^{2}$, respectively), have a history of CVD (19\% versus 6\%) and be less physically active (12\% versus $29 \%$; Table 1 ). Participants with diabetes were also more likely to be taking lipidmodifying agents (65.1\% versus $23.2 \%$ ) and using antihypertensive medication $(3.8 \%$ versus $1.5 \%)$. Only a small number of participants had type 1 diabetes $(n=3)$, had self-reported diabetic retinopathy $(n=9)$ or were taking prescribed medication as a treatment for diabetes $(n=85)$. Comparisons of participant characteristics between those with good-quality retinal imaging included in the study and those excluded due to poor-quality retinal imaging are presented in Supplementary Table 1.

Comparisons of CRAE and CRVE from left and right eye images from 75 participants were not significantly different $(\mathrm{PCrae}=0.08$; PCrve $=0.89)$. Table 2 summarises mean 
Table 1 Participant summary characteristics

\begin{tabular}{|c|c|c|c|c|}
\hline Participant characteristics & All $(n=1762)$ & No diabetes $(n=1553)$ & Diabetes $(n=209)$ & $P$-value \\
\hline Mean age (years, SD) & $62.1 \pm 8.5$ & $61.7 \pm 8.4$ & $65.1 \pm 9.0$ & $<0.01$ \\
\hline Female, $n(\%)$ & $944(53.6)$ & $841(54.2)$ & $103(49.3)$ & 0.19 \\
\hline Smoking status, yes $n(\%)$ & $171(9.7)$ & $149(9.6)$ & $22(10.5)$ & 0.67 \\
\hline Alcohol consumption, non-drinker, $n(\%)$ & $393(22.3)$ & $323(20.8)$ & $70(33.5)$ & $<0.01$ \\
\hline Physical activity level, highly active, $n(\%)$ & $481(27.3)$ & $455(29.3)$ & $26(12.4)$ & $<0.01$ \\
\hline Cardiovascular disease, yes $n(\%)$ & $134(7.6)$ & $94(6.1)$ & $40(19.1)$ & $<0.01$ \\
\hline Hypertension, $n(\%)$ & $643(36.5)$ & $553(35.6)$ & $90(43.1)$ & 0.04 \\
\hline Mean eGFR (ml/min/1.73m²) & $82.2(14.8)$ & $82.8(14.4)$ & $77.4(17.3)$ & $<0.01$ \\
\hline Mean BMI $\left(\mathrm{kg} / \mathrm{m}^{2}, \mathrm{SD}\right)$ & $28.6 \pm 4.9$ & $28.2 \pm 4.7$ & $31.4 \pm 5.7$ & $<0.01$ \\
\hline Mean arterial blood pressure (mm Hg, SD) & $98.0 \pm 12.3$ & $97.8 \pm 12.4$ & $99.6 \pm 11.5$ & 0.05 \\
\hline Mean triglyceride (mmol/L, SD) & $1.7 \pm 0.9$ & $1.6 \pm 0.9$ & $1.9 \pm 1.2$ & $<0.01$ \\
\hline Mean HDL cholesterol (mmol/L, SD) & $1.6 \pm 0.5$ & $1.7 \pm 0.5$ & $1.4 \pm 0.4$ & $<0.01$ \\
\hline Mean LDL cholesterol (mmol/L, SD) & $3.4 \pm 1.1$ & $3.5 \pm 1.1$ & $2.8 \pm 1.1$ & $<0.01$ \\
\hline Mean HbA1c (mmol/mol, SD) & $39.4 \pm 9.8$ & $37.0 \pm 4.2$ & $57.4 \pm 17.6$ & $<0.01$ \\
\hline Using lipid modifying agents, $n(\%)$ & $497(28.2)$ & $361(23.2)$ & $136(65.1)$ & $<0.01$ \\
\hline Using antihypertensive drugs, $n(\%)$ & $31(1.8)$ & $23(1.5)$ & $8(3.8)$ & 0.02 \\
\hline
\end{tabular}

Values are $n(\%)$ for categorical variables and mean \pm SD for continuous variables. $P$ values were calculated by independent samples $\mathrm{t}$ and chisquared tests. Hypertension was defined as a systolic blood pressure $\geq 140 \mathrm{~mm} \mathrm{Hg}$ or a diastolic blood pressure $\geq 90 \mathrm{~mm} \mathrm{Hg}$

$e G F R$ estimated glomerular filtration rate, $H b A l c$ glycated haemoglobin, $B M I$ body mass index, $H D L$ high-density lipoprotein, $L D L$ low-density lipoprotein, $S D$ standard deviation

RMPs. Both mean arterial and venular tortuosity were significantly different between those with and without diabetes $(P<0.05$; Table 2$)$.

In unadjusted and minimally adjusted regression, AVR, arteriolar tortuosity and venular tortuosity were significantly associated with diabetes (minimally adjusted odds ratio $[\mathrm{OR}]=0.85 ; 95 \%$ confidence intervals $[\mathrm{CI}] 0.73$, $0.99 ; P=0.04, \mathrm{OR}=1.18 ; 95 \%$ CI $1.02,1.37 ; P=0.03$ and $\mathrm{OR}=1.20 ; 95 \% \mathrm{CI} 1.04,1.38 ; P=0.01$, respectively), although these did not remain significant following adjustment for the potential confounding effects of smoking status, alcohol consumption, CVD, MABP, PA, BMI, triglycerides, HDL and LDL $(\mathrm{OR}=0.88 ; 95 \%$
CI $0.75,1.04 ; P=0.13, \mathrm{OR}=1.13 ; 95 \%$ CI $0.96,1.32$; $P=0.13$ and $\mathrm{OR}=1.14 ; 95 \% \mathrm{CI} 0.97,1.32 ; P=0.11$, respectively; Table 3 ). No additional associations between diabetes and RMPs were detected. A sensitivity analysis that excluded 224 control participants with a HbA1c level between 42 and $47 \mathrm{mmol} / \mathrm{mol}$ did not differ significantly from the findings of the primary analysis (data not shown). In a sensitivity linear regression analysis of associations between RMPs and HbA1c, only arteriolar tortuosity was significantly associated with $\mathrm{HbA} 1 \mathrm{c}$ in both unadjusted and minimally adjusted models $(\beta=0.006 ; 0.001,0.010$; $P=0.02$ ), but this did not remain significant in the fully adjusted model (Supplementary Table 2).

Table 2 Summary of participant retinal microvascular parameters

\begin{tabular}{|c|c|c|c|c|}
\hline Retinal microvascular parameters & All $(n=1762)$ & Non-diabetic $(n=1553)$ & Diabetic $(n=209)$ & $P$-value \\
\hline Mean CRAE (PX, SD) & $29.655 \pm 2.196$ & $29.670 \pm 2.204$ & $29.545 \pm 2.139$ & 0.44 \\
\hline Mean CRVE (PX, SD) & $40.898 \pm 3.275$ & $40.854 \pm 3.254$ & $41.230 \pm 3.423$ & 0.12 \\
\hline Mean AVR (SD) & $0.728 \pm 0.062$ & $0.729 \pm 0.062$ & $0.720 \pm 0.061$ & 0.04 \\
\hline Mean fractal dimension arteriolar (SD) & $1.558 \pm 0.051$ & $1.557 \pm 0.051$ & $1.561 \pm 0.053$ & 0.36 \\
\hline Mean fractal dimension venular (SD) & $1.540 \pm 0.050$ & $1.540 \pm 0.050$ & $1.541 \pm 0.053$ & 0.92 \\
\hline Mean tortuosity arteriolar $(\mathrm{SD})^{\mathrm{a}}$ & $0.111 \pm 0.148$ & $0.108 \pm 0.138$ & $0.133 \pm 0.208$ & 0.02 \\
\hline Mean tortuosity venular (SD) ${ }^{\mathrm{a}}$ & $0.068 \pm 0.105$ & $0.066 \pm 0.099$ & $0.083 \pm 0.140$ & 0.01 \\
\hline
\end{tabular}

Values are mean \pm SD for continuous variables. $P$ values were calculated by independent samples $\mathrm{t}$ tests

$C R A E$ central retinal arteriolar equivalent, $C R V E$ central retinal venular equivalent, $A V R$ retinal arteriolar/venular ratio, $S D$ standard deviation, $P X$ pixels

${ }^{\text {a }}$ Tortuosity values were multiplied by 1000 in order to be shown in table. $P<0.05$ was considered statistically significant 
Table 3 Logistic regression analysis of retinal microvascular parameters and diabetic status

\begin{tabular}{|c|c|c|c|c|c|c|}
\hline \multirow[b]{2}{*}{ Retinal parameter } & \multicolumn{3}{|c|}{ Minimally adjusted } & \multirow[b]{2}{*}{ OR } & \multicolumn{2}{|c|}{ Fully adjusted } \\
\hline & OR & $95 \% \mathrm{CI}$ & $P$-value & & $95 \% \mathrm{CI}$ & $P$-value \\
\hline $\operatorname{CRAE}(\mathrm{PX})^{\mathrm{a}}$ & 0.92 & $0.79,1.07$ & 0.28 & 0.97 & $0.82,1.14$ & 0.67 \\
\hline $\operatorname{CRVE}(\mathrm{PX})^{\mathrm{a}}$ & 1.10 & $0.95,1.27$ & 0.19 & 1.11 & $0.95,1.29$ & 0.21 \\
\hline $\mathrm{AVR}^{\mathrm{a}}$ & 0.85 & $0.73,0.99$ & 0.04 & 0.88 & $0.75,1.04$ & 0.13 \\
\hline Fractal dimension arteriolar ${ }^{\mathrm{a}}$ & 1.10 & $0.95,1.28$ & 0.21 & 1.15 & $0.98,1.36$ & 0.09 \\
\hline Fractal dimension venular ${ }^{\mathrm{a}}$ & 1.04 & $0.89,1.21$ & 0.64 & 1.02 & $0.87,1.21$ & 0.77 \\
\hline Tortuosity arteriolar ${ }^{\mathrm{a}, \mathrm{b}}$ & 1.18 & $1.02,1.37$ & 0.03 & 1.13 & $0.96,1.32$ & 0.13 \\
\hline Tortuosity venular ${ }^{\mathrm{a}, \mathrm{b}}$ & 1.20 & $1.04,1.38$ & 0.01 & 1.14 & $0.97,1.32$ & 0.11 \\
\hline
\end{tabular}

$C R A E$ central retinal arteriolar equivalent, $C R V E$ central retinal venular equivalent, $A V R$ retinal arteriolar/venular ratio, $C I$ confidence interval, $O R$ odds ratio, $P X$ pixels

${ }^{a}$ RMPs were transformed into standardised Z-scores before inclusion in regression models

${ }^{\mathrm{b}}$ Tortuosity values were log-transformed before inclusion in regression models to produce normal distribution. Minimally adjusted models included age and sex, with fully adjusted models also including smoking status, alcohol consumption, CVD, MABP and physical activity level, body mass index, triglycerides and high- and low-density lipoprotein levels

\section{Discussion}

Advances in retinal imaging technologies have enabled improved quantitative assessment of RMPs as surrogates of microvascular health [33]. Several studies have reported associations between RMPs and diabetes, but the findings between longitudinal and cross-sectional studies have not always been consistent, in part due to variation in the reported unit measures included in statistical analyses (e.g. pixels, microns, standardised Z-scores and per standard deviation increase) and the availability of potential confounding variables considered in adjusted models [18-27, 34-39]. In this cross-sectional analysis of 1762 older persons from the NICOLA study categorised as either diabetic or non-diabetic, we found that AVR and arteriolar and venular tortuosity were significantly associated with diabetes when adjusted for age and sex (Table 3), but none remained significantly associated with diabetes following adjustment for multiple potential confounders. Other similar populationbased studies, such as the Rotterdam Study, also failed to detect significant associations between RMPs and diabetes status [38]. In sensitivity analyses that excluded those with pre-diabetes and evaluated associations between RMPs and $\mathrm{HbA1c}$, similar findings to the primary analysis presented were also identified. A recent systematic review and metaanalysis reported retinal venular widening in association with an increased risk of incident diabetes [3]. Kifley et al. also reported wider retinal arteriolar calibre in association with diabetes [19,37], although this finding contrasted with the retinal arteriolar narrowing reported by Wong and colleagues $[34,35]$. Jegnathan and colleagues reported wider retinal arteriolar and venular calibre in association with diabetes and increasing glucose levels [18]. Although our findings suggested retinal arteriolar narrowing and venular dilation was associated with diabetes, these associations did not remain significant following adjustment for potential confounders. Nevertheless, given the meta-analysis performed by Sabanayagam and colleagues had more than ten times the number of diabetes cases, power to detect associations is likely to have been much reduced in our study [3].

Experimental studies have implicated diabetes-induced microvascular modification and structural morphological changes in retinal vessel complexity and density defined by fractal dimension [40]. Variation in retinal fractal dimension may be increased under hyperglycaemic conditions, leaving the microvasculature susceptible to further damage from additional vascular risk factors [35]. Few studies have evaluated associations between retinal fractal dimension and tortuosity with diabetic status [24-27]. Broe et al. found retinal vascular fractal dimension to be associated with microvascular dysfunction in diabetes that may be indicative of common pathogenic pathways, making it a possible means of stratifying diabetic risk [27]. Yau and colleagues also evaluated associations between retinal fractal dimension and diabetes. They reported that increased fractal dimension was significantly associated with participants with diabetes, but not in those with impaired glucose metabolism [26]. Sasongko et al. reported retinal arteriolar and venular tortuosity were both significantly increased in participants with diabetes, without the presence of diabetic retinopathy. They concluded that individuals with diabetes had more tortuous retinal vessels than controls without diabetes [24]. Owen and colleagues showed a graded association with both tortuosity and width of retinal venules and metabolic risk factors such as HbA1c, even among people without clinical diabetes [25]. The directions of effect in those with diabetes were also similar to those reported in our study for both, 
arteriolar and venular tortuosity in unadjusted and minimally adjusted models, despite not remaining significant in the fully adjusted models.

There were several limitations to our study. Firstly, although we adjusted for potential confounders, there is still the possibility of residual confounding. Secondly, the mainly Caucasian study population aged greater than 50 years may be a limitation to the generalisability of any findings to other populations of different ages and ethnicities. Finally, variation in retinal imaging software based on different algorithms may make comparisons between studies challenging [3].

Despite these limitations, our study had several strengths including the population-based design. The NICOLA study included well-characterised participants that captured a broad range of demographic factors and clinical variables including comorbidities and medications used that enable comprehensive characterisation of diabetic status. In addition, the availability of optic disc-centred retinal fundus images provides improved sensitivity for the quantification of RMPs compared to macula-centred images, which are largely restricted to the retinal temporal arcades. Although assessment of retinal images was based on a single eye, previous studies have reported a high correlation of RMPs with the fellow eye, supported by our sensitivity analysis of comparisons of vessel diameters in 75 participants [41-43].

In conclusion, although previous studies have reported contrasting associations between diabetes and RMPs, we failed to detect any significant associations in this older community-based cohort. The direction of effect that we observed supported those from a previous large meta-analysis but consistency around confounding variables, sample size and variation in algorithm-based measurement increases the challenges of cross-study comparisons.

\begin{abstract}
Abbreviations NICOLA: The Northern Ireland Cohort for the Longitudinal Study of Ageing; BMI: Body mass index; HDL: Highdensity lipoprotein; LDL: Low-density lipoprotein; CRAE: Central retinal arteriolar equivalent; CRVE: Central retinal venular equivalent; AVR: Retinal arteriolar/venular ratio; SD: Standard deviation; PX: Pixels; CPH: Centre for Public Health; CVD: Cardiovascular disease; SBP: Systolic blood pressure; DBP: Diastolic blood pressure; CI: Confidence intervals; $\beta$ : Beta value; $\mu \mathrm{m}$ : Microns; ICCs: Intraclass correlation coefficients; VAMPIRE: Vessel Assessment and Measurement Platform for Images of the Retina; MABP: Mean arteriole blood pressure; RMPs: Retinal microvascular parameters; Yrs: Years; HbA1c: Glycated haemoglobin
\end{abstract}

Supplementary information The online version contains supplementary material available at https://doi.org/10.1007/s11845-021-02704-1.

Acknowledgements We are grateful to all the participants of the NICOLA Study, and the whole NICOLA team, which includes nursing staff, research scientists, clerical staff, computer and laboratory technicians, managers and receptionists.

Author contribution RON undertook retinal measurements, data analysis and was the main contributor in writing the manuscript. All the authors revised the manuscript critically for important intellectual content and are accountable for all aspects of the work in relation to its accuracy and integrity. Finally, all the authors read and approved the final manuscript before submission.

Funding Rachael O'Neill was supported by a Ph.D. studentship from the Department for Education, Northern Ireland. This work was supported by the following funders who provide core financial support for the NICOLA Study: the Atlantic Philanthropies; the Economic and Social Research Council; the UKCRC Centre of Excellence for Public Health Northern Ireland; the Centre for Ageing Research and Development in Ireland; the Office of the First Minister and Deputy First Minister; the Health and Social Care Research and Development Division of the Public Health Agency; the Wellcome Trust/Wolfson Foundation; and Queen's University Belfast. The authors alone are responsible for the interpretation of the data, and any views or opinions presented are solely those of the authors and do not necessarily represent those of the NICOLA Study team.

Availability of data and material The data that support the findings of this study are available from the Northern Ireland Cohort for Longitudinal Ageing (NICOLA), but restrictions apply to the availability of this data. Data access is available by request through the NICOLA Data Access Committee.

\section{Declarations}

Ethics approval and consent to participate Written informed consent was obtained from participants prior to taking part following ethical approval from the Queen's University Belfast School Research Ethics Committee in compliance with the Declaration of Helsinki (SREC $12 / 23)$.

Conflict of interest The authors declare no competing interests.

Open Access This article is licensed under a Creative Commons Attribution 4.0 International License, which permits use, sharing, adaptation, distribution and reproduction in any medium or format, as long as you give appropriate credit to the original author(s) and the source, provide a link to the Creative Commons licence, and indicate if changes were made. The images or other third party material in this article are included in the article's Creative Commons licence, unless indicated otherwise in a credit line to the material. If material is not included in the article's Creative Commons licence and your intended use is not permitted by statutory regulation or exceeds the permitted use, you will need to obtain permission directly from the copyright holder. To view a copy of this licence, visit http://creativecommons.org/licenses/by/4.0/.

\section{References}

1. Benito MH, Fernandez-Reyes MJ, Sanchez R (2010) Implications outcome of chronic kidney disease in elderly. Nefrologia 30:151-157

2. Kalyani RR, Golden SH, Cefalu WT (2017) Diabetes and ageing: unique considerations and goals of care. Diabetes Care 40:440-443

3. Sabanayagam C, Lye WK, Klein R et al (2015) Retinal microvascular calibre and risk of diabetes mellitus: a systematic review and participant-level meta-analysis. Diabetologia $58: 2476-2485$ 
4. Salinas M, Garrigos-Lopez M, Flores E et al (2018) Glycated haemoglobin: a powerful tool not used enough in primary care. J Clin Lab Anal 32:e22310

5. International Expert Committee TIE (2009) International Expert Committee report on the role of the A1C assay in the diagnosis of diabetes. Diabetes Care 32:1327-1334

6. Clark MG, Barrett EJ, Wallis MG et al (2002) The microvasculature in insulin resistance and type 2 diabetes. Semin Vasc Med 2:21-31

7. Clark MG (2008) Impaired microvascular perfusion: a consequence of vascular dysfunction and a potential cause of insulin resistance in muscle. Am J Physiol Endocr Metab 295:e732-e750

8. Chawla A, Chawla R, Jaggi S (2016) Microvascular and macrovascular complications in diabetes mellitus: distinct or continuum. Indian J Endocr Metab 20(4):546-551

9. Struijker-Boudier HA, Heijnen BF, Liu YP et al (2012) Phenotyping the microcirculation. Hypertension 60:523-527

10. Struijker-Boudier HA, Rosei AE, Bruneval P et al (2007) Evaluation of the microcirculation in hypertension and cardiovascular disease. Euro Heart J 28:2834-2840

11. Liew G, Wang JJ, Mitchell P, Wong TY (2008) Retinal vascular imaging: a new tool in microvascular disease research. Circ Cardiovasc Imaging 1:156-161

12. Gramatikov BI (2014) Modern technologies for retinal scanning and imaging: an introduction for the biomedical engineer. Biomed Eng $13: 52$

13. Kim JA, Montagnani M, Koh KK et al (2006) Reciprocal relationships between insulin resistance and endothelial dysfunction: molecular and pathophysiological mechanisms. Circulation 113:1888-1904

14. DaienV, Carriere I, Kawasaki R et al (2013) Retinal vascular caliber is associated with cardiovascular biomarkers of oxidative stress and inflammation: the POLA study. PLoS One 8:e71089

15. Ikram MK, de Jong FJ, Vingerling JR et al (2004) Are retinal arteriolar or venular diameters associated with markers for cardiovascular disorders? The Rotterdam Study. Investig Ophthalmol Vis Sci 45:2129-2134

16. Klein R, Klein BE, Knudtson MD et al (2006) Are inflammatory factors related to retinal vessel caliber? The Beaver Dam Eye Study. Arch Ophthalmol 124:87-94

17. Wong TY, Islam FM, Klein R et al (2006) Retinal vascular caliber, cardiovascular risk factors, and inflammation: the multi-ethnic study of atherosclerosis (MESA). Investig Ophthalmol Vis Sci 47:2341-2350

18. Jeganathan VS, Sabanayagam C, Tai ES et al (2009) Retinal vascular caliber and diabetes in a multiethnic Asian population. Microcirculation 16:534-543

19. Kifley A, Wang JJ, Cugati S et al (2007) Retinal vascular caliber, diabetes, and retinopathy. Am J Ophthalmol 143:1024-1026

20. Nguyen TT, Wang JJ, Sharrett AR et al (2008) Relationship of retinal vascular caliber with diabetes and retinopathy: the Multi-Ethnic Study of Atherosclerosis (MESA). Diabetes Care 31:544-549

21. Cheung CY, Ikram MK, Klein R et al (2015) The clinical implications of recent studies on the structure and function of the retinal microvasculature in diabetes. Diabetologia 58:871-885

22. Phan K, Mitchell P, Liew G et al (2018) Associations between retinal arteriolar and venular calibre with the prevalence of impaired fasting glucose and diabetes mellitus: a cross-sectional study. PLoS One 13(5): $\mathrm{e} 0189627$

23. Li W, Schram MT, Berendschot TTJM et al (2020) Type 2 diabetes and $\mathrm{HbA} 1 \mathrm{c}$ are independently associated with wider retinal arterioles: the Maastricht study. Diabetologia 63:1408-1417

24. Sasongko MB, Wong TY, Nguyen TT et al (2011) Retinal vascular tortuosity in persons with diabetes and diabetic retinopathy. Diabetologia 54:2409-2416

25. Owen CG, Rudnicka AR, Welikala RA et al (2019) Retinal vasculometry associations with cardiometabolic risk factors in the
European Prospective Investigation of Cancer-Norfolk study. Ophthalmology 126:96-106

26. Yau JWY, Kawasaki R, Islam FM et al (2010) Retinal fractal dimension is increased in persons with diabetes but not impaired glucose metabolism: the Australian Diabetes, Obesity and Lifestyle (AusDiab) study. Diabetologia 53:2042-2045

27. Broe R, Rasmussen ML, Frydkjaer-Olsen U et al (2014) Retinal vascular fractals predict long-term microvascular complications in type 1 diabetes mellitus: the Danish Cohort of Pediatric Diabetes 1987 (DCPD1987). Diabetologia 57:2215-2221

28. O'Neill RA, Maxwell AP, Kee F et al (2020) Association of retinal venular tortuosity with impaired renal function in the Northern Ireland Cohort for the Longitudinal Study of Ageing. BMC Nephrol 21:382

29. Fetit AE, Doney AS, Hogg S et al (2019) A multimodal approach to cardiovascular risk stratification in patients with type 2 diabetes incorporating retinal, genomic and clinical features. Sci Rep $9(1): 3591$

30. McKay GJ, Paterson EN, Maxwell AP et al (2018) Retinal microvascular parameters are not associated with reduced renal function in a study of individuals with type 2 diabetes. Sci Rep 8(1):3931

31. Metcalf KM, Baquero BI, Coronado MLC et al (2018) Calibration of the global physical activity questionnaire to Accelermetry measured physical activity and sedentary behaviour. BMC Public Health $18: 412$

32. Mumu SJ, Ali L, Barnett A et al (2017) Validity of the global physical activity questionnaire (GPAQ) in Bangladesh. BMC Public Health 17:650

33. Ikram MK, Ong YT, Cheung CY et al (2013) Retinal vascular caliber measurements: clinical significance, current knowledge and future perspectives. Ophthalmologica 229:125-136

34. Wong TY, Klein R, Sharrett AR et al (2002) Retinal arteriolar narrowing and risk of diabetes mellitus in middle-aged persons. JAMA 287:2528-2533

35. Wong TY, Shankar A, Klein R et al (2005) Retinal arteriolar narrowing, hypertension, and subsequent risk of diabetes mellitus. Arch Intern Med 165:1060-1065

36. Nguyen TT, Wang JJ, Islam FM et al (2008) Retinal arteriolar narrowing predicts incidence of diabetes: the Australian Diabetes, Obesity and Lifestyle (AusDiab) Study. Diabetes 57:536-539

37. Kifley A, Wang JJ, Cugati S et al (2008) Retinal vascular caliber and the long-term risk of diabetes and impaired fasting glucose: the Blue Mountains Eye Study. Microcirculation 15:373-377

38. Ikram MK, Janssen JA, Roos AM et al (2006) Retinal vessel diameters and risk of impaired fasting glucose or diabetes: the Rotterdam study. Diabetes 55:506-510

39. Muris DM, Houben AJ, Schram MT et al (2012) Microvascular dysfunction is associated with a higher incidence of type 2 diabetes mellitus: a systematic review and meta-analysis. Arterioscl Throm Vas 32:3082-3094

40. Dosso AA, Leuenberger PM, Rungger-Brandle E (1999) Remodeling of retinal capillaries in the diabetic hypertensive rat. Investig Ophthalmol Vis Sci 40:2405-2410

41. Wong TY, Knudtson MD, Klein BE et al (2004) Computer-assisted measurement of retinal vessel diameters in the Beaver Dam Eye Study: methodology, correlation between eyes, and effect of refractive errors. Ophthalmol 111(6):1183-1190

42. Cheung N, Tikellis G, Saw SM et al (2007) Relationship of axial length and retinal vascular caliber in children. Am J Ophthalmol 144(5):658-662

43. Leung H, Wang JJ, Rochtchina E et al (2003) Computer-assisted retinal vessel measurement in an older population: correlation between right and left eyes. Clin Exp Ophthalmol 31(4):326-330

Publisher's Note Springer Nature remains neutral with regard to jurisdictional claims in published maps and institutional affiliations. 